\title{
Analysis of Metacognition Difficulties and Mathematical Connections of Students using the Jigsaw Type Cooperative Learning Model
}

\author{
Nurvita \\ Post Graduate Mathematics Education \\ State University of Medan \\ Indonesia \\ nurvita1914@gmail.com
}

\author{
Bornok Sinaga \\ Mathematics Education \\ State University of Medan \\ Indonesia
}

\author{
Mukhtar \\ Mathematics Education \\ State University of Medan \\ Indonesia
}

\begin{abstract}
The aims of the study was the level of mathematical metacognition and connection ability, the process of answering the problem of metacognition and connection problems, the difficulty of students solving metacognition and connection problems of high, medium, low and very low ability. Qualitative analysis of descriptive analysis. Research Results metacognitive ability is very low 13 percent, low 37 percent, moderate 18 percent and high 32 percent, connection ability is very low 16 percent, low 39 percent, moderate 29 percent and high 16 percent, the process of student answers is described there is no conflict with the agreement exist in mathematics. Metacognition of high-level students meets planning indicators, monitoring indicators and assessment indicators, is capable of fulfilling planning indicators, does not meet monitoring indicators and assessment indicators, low-ability students do not meet planning indicators, monitor indicators and assessment indicators, very low ability does not meet planning indicators, planning indicators and assessment indicators, mathematical connections of high-ability students fulfill connection indicators between mathematical topics, connections with other sciences and connections with real life, are capable of not meeting connection indicators between mathematical topics, fulfilling connection indicators with other sciences and connections with real life, very low ability does not meet the connection indicators between mathematical topics, connections with other sciences and connections with real.
\end{abstract}

Keywords- analysis of metacognition difficulties, student mathematical connections, type jigsaw cooperative learning model

\section{INTRODUCTION}

Education plays an important role in the life of a nation because education is a process of delivering culture from one generation to the next, which includes skills, knowledge, attitudes and values and certain behavioral patterns. The purpose of learning mathematics shows that one of the roles of mathematics is to prepare students to be able to deal with changing circumstances or challenges in life and in an everevolving world. The preparations are made through the exercise of making decisions and conclusions on the basis of logical, rational, critical, careful, honest, efficient and effective thinking.
In addition, students are expected to be able to use mathematics and mathematical thinking in their daily lives. Through the process of learning to live together in peace and harmony, students socialize and communicate in mathematics. [1] NCTM (2000) states that "there are several aspects included in the ability to think mathematically including the ability to solve mathematical problems, mathematical communication, mathematical reasoning and proof, mathematical connections and mathematical representations". Of the five mathematical thinking abilities, without ignoring the other abilities, the ability of metacognition and mathematical connections are two important parts in the activities and uses of mathematics that students learn.

Metacognition is defined as thinking about our own thinking which is an interaction between three important aspects, namely: knowledge of our own thought processes, control or self-regulation, and beliefs and intuition. Metacognition as awareness and management of cognitive processes and products owned by a person or simply referred to as thinking about thinking. This interaction is very important because our knowledge of our cognitive processes can help us organize the things around us and choose strategies to further enhance our cognitive abilities. Based on observations made at the firts secondary school of one lawe bulan in southeastern aceh, it can be seen from the observations made in class eight the firts secondary school of one lawe bulan in southeastern aceh that students have not been able to solve problems properly.

The situation on the ground also shows that, learning by using the old paradigm makes students passive, thus causing a decrease in students' mathematical abilities. This is not very supportive in learning mathematics which has abstract properties that require metacognition abilities. These observations indicate that students do not control and monitor the metacogical processes when performing procedures so they are not aware of their cognitive structure related to procedural. Student awareness related to the procedural knowledge it possesses is a component of metacognitive knowledge. Mathematical connection is one of the abilities that is the goal of learning mathematics. Because by having the ability to connect with students, can help students succeed in learning. 
Good ability to connect between topics in mathematics, mathematics with outside mathematics. Or the ability of mathematical connections with the everyday world of students, that building mathematical connections is a very important activity carried out by teachers and students in learning mathematics so that it can take the form of understanding students' mathematics, [2] Hasratuddin (2015) the importance of mathematical connections aims so that students can see the linkages between concepts in mathematics so that students do not view mathematics as mere material.With the existence of mathematical connections learning about mathematics is no longer a boring science, because students are required to be able to link their knowledge with their real world, are required to be able to solve by connecting other sciences or with previous concepts.

Through mathematical connections the learning of mathematics becomes easier for children to understand. Meanwhile, based on findings in the field it is known that students' mathematical connection ability is still low. Similar to the findings of the researcher at the beginning of the observation about the problematic metacognition of students, the mathematical connections of students in junior high schools were also problematic. This can be seen from the difficulty of students solving problems. The picture that can be obtained from the students' answers is that students have not been able to solve mathematical connection ability questions correctly. This answer sheet shows that students 'mathematical connection abilities are still low, students' difficulties in solving problems related to writing problems of daily life into the form of mathematical models

Students also still have difficulty in connecting between objects and concepts in mathematics, in addition to students also still have difficulty in determining what formulas will be used when faced with problems related to everyday life problems. Difficulties of students in learning mathematics that have been explained above are elements of mathematical connection ability so that the results of observations indicate the difficulties of mathematical connections of students that are still not optimal.Difficulties of students in learning mathematics that have been explained above are elements of mathematical connection ability so that the results of observations indicate the difficulties of mathematical connections of students that are still not optimal.

The above problem can be solved correctly if the student is able to understand and the ability of mathematical connections in finding relationships of various representations of concepts and procedures, understanding the relationships between mathematical topics, applying mathematics in other fields or in everyday life, understanding equivalent representations of concepts, seeking the relationship of one procedure with another procedure in equivalent representation, and applying the relationship between mathematical topics and between mathematical topics with topics outside mathematics is still low, even the difficulty of students in solving problems of mathematical connections without the process of solving students' answers.

Based on observations and observations by the author of the learning methods applied by teachers in the class in delivering subject matter less actively involving students because students are less encouraged to develop thinking skills. The learning that is carried out is conventional learning that is centered on the teacher, the teacher dominates the learning so that the involvement of students in the learning process is still lacking. Seeing the importance of mathematics learning that emphasizes the ability of students' metacognition and mathematical connections, it is necessary to learn accordingly for this purpose. The use of a jigsaw cooperative learning model is an alternative to improve students' metacognition abilities and mathematical connections.

\section{THEORETICAL FRAMEWORK}

\section{A. Metacognition}

The idea of metacognition was first introduced by Flavell from Stanford University around 1975 [3] Zahra, (2016), he used the term metacognition to express the following definition. Metacognition refers to a person's knowledge of cognitive processes and their own products or anything related to them, for example, information or data properties that are relevant to learning.

Metacognition refers, inter alia, to active monitoring and the consequent regulation and orchestration of this process in relation to the cognitive objects or data they carry, usually in serving a number of concrete goals or objectives. Understanding flavell statements shows that metacognition is one's knowledge of metacognition is one's knowledge of the process of cognition, products or anything related to the thought process, including learning about the relationship of the properties of information or data.

The ability of metacognition associated with students' thinking processes about thinking so as to find the right strategy in solving problems. Each student has a different ability to deal with problems. [4] Wilson (2004) awareness of one's thoughts can be observed. So that the level of awareness of students' thinking can be observed in the steps taken in solving a problem. Planning indicators, monitoring indicators and assessment indicators.

\section{B. Connection}

Connection is derived from the word connection in English which means relationship. A general connection is a relationship or connection. Connections in connection with mathematics called mathematical connections can be interpreted as internal and external connections. Internal connection is the relationship between mathematical concepts related to mathematics itself and external relations, namely the relationship between mathematics and everyday life.The importance of this mathematical connection aims so that students can see the relationship between concepts in mathematics so that students do not see mathematics as a collection of material.

Therefore, in introducing new concepts it is necessary to pay attention to concepts that have been studied previously. Likewise the relationship between mathematics and everyday life. The mathematical connection skills possessed by students will bring these students into the integration of mathematics 
into the habits of everyday life where when students can associate mathematical ideas with everyday experiences, students become aware of the usefulness of mathematics.

[5] Rohendi and Dulpaja (2013) The ability of mathematical connections is included in the ability to think higher level. Mathematical connection means the capacity above the information provided, with a critical attitude to evaluate something and have metacognitive awareness, and the ability to solve problems. Indicators regarding mathematical connections are as follows:

a. Seek and understand the relationship between various representations of concepts and procedures.

b. Using mathematics in other fields or everyday life.

c. Understand the equivalent representation of the same concept or procedure.

d. Look for connections from one procedure to another in an equivalent representation.

e. Use connections between math topics and between math topics and other topics.

The mathematical connection in question is the ability of students to look for relationships between topics in mathematics, look for relationships between mathematical topics with other disciplines, and the ability of students to apply mathematical concepts in everyday life. From the explanation above it can be concluded that mathematical connection ability is a higher level thinking ability that can evaluate things critically and have problem solving abilities and awareness of metacognition, connections between connections between mathematical topics, connections with other sciences and connections with real life, then researchers use connections with indicators of connections between mathematical topics, connections with other sciences and connections with real life.

\section{Jigsaw Type Cooperative Learning Model}

The jigsaw technique, which was introduced by Aranson the aims to enhance teamwork and create team cohesiveness among students through division of tasks "involving each student in the group to accept learning responsibilities. Thus, students work in two different groups: the main group and the jigsaw group. Jigsaw cooperative learning is one type of cooperative learning that encourages students to be active and help one another in mastering subject matter to achieve maximum achievement.

[6] Rusma (2010) cooperative learning jigsaw model is a cooperative learning model by means of students learning in small groups of four to six heterogeneous people and students working together positive interdependence and responsible responsibility independent ". In this cooperative jigsaw model students have many opportunities to express opinions and process the information obtained and can improve communication skills, group members are responsible for the success of the group and the completeness of the material learned and can convey information to other groups.

The steps of the Jigsaw type cooperative learning model are stage 1 conveying objectives and motivating students, stage 2 presenting information, stage 3 organizing students into study groups, stage 4 guiding work and study groups, stage 5 evaluation and stage 6 giving rewards.

\section{RESEARCH QUESTION}

1. What is the level of metacognition ability of students using a jigsaw cooperative learning model in class eight the firts secondary school of one lawe bulan in southeastern aceh.

2. What is the level of connection ability of students using a jigsaw cooperative learning model in class eight the firts secondary school of one lawe bulan in southeastern aceh.

3. How is the process of answering the problem solving students' metacognition and mathematical connections using a jigsaw cooperative learning model.

4. How students have difficulty solving students metacognitive problems and mathematical connections on high, medium, low and very low abilities.

\section{RESEARCH METHOD}

The subjects in this study were eighth grade students of SMP Negeri 1 Lawe Bulan Aceh Tenggara who were given a treatment with a jigsaw cooperative learning model that helped 38 people. While the learning material provided is flat side space. Type of qualitative research. The criterion for taking the subject is to use four criteria which are based on indicators of student ability. Error answers and unique answers. through the lens of indicators student answer sheets are grouped into four categories of answers namely answer sheets of high, medium, low and very low ability students.

Data collection methods needed in this study are metacognition tests and students' mathematical connections, interviews, observations or observations, and documentation. This study uses learning tools and research instruments with validity and testing of learning and research tools with instruments and research. Data analysis in this study uses qualitative data analysis where data analysis is performed after giving a learning action. Activities in data analysis use the Miles and Huberman Model, namely data reduction, data display, and drawing conclusions / data verification.

[7] Sugiyono (2009) states the data analysis techniques provided by Miles and Huberman and Spradley complement each other. In each stage of the study, Miles and Huberman used the steps of reduction, data display, and verification. This third step can be done in all qualitative research processes, namely description, focus, and selection.

\section{DATA ANALYSIS, RESULT AND DISCUSSION}

Data analysis in this study uses qualitative data analysis where data analysis is performed after giving a learning action. According to [8] Bogdan In Trianto (2011) argues that qualitative data analysis is the process of systematically searching and compiling data obtained from interviews, field 
notes, and other materials so that it is easy to understand so that it can be informed to people other.

The data analysis is done by organizing the data, breaking it down into units, synthesizing it, arranging it into patterns, choosing what is important, and what will be studied so that conclusions can be made to be conveyed to others. Activities in data analysis use the Miles and Huberman Models, namely data reduction, data display, and conclusion drawing / verification data. In each stage of the research Miles and Huberman uses the steps of reduction, data display, and verification.

These three steps can be carried out at all stages in the qualitative research process, namely the description, focus, and selection stages. From the statement above that the two methods are also complementary but the Spradley method actually departs from the broad, then focuses, and extends more meaningful qualitative research using the Miles and Huberman method where the three steps of data analysis also exist at all stages in the qualitative research process.

After carrying out learning using a jigsaw cooperative learning model on the material to build flat side space, continued tests on students to see the ability of metacognition. Student answer sheets corrected based on scoring guidelines are graded. The level of metacognition ability of students is presented in Table 1 below.

TABLE 1. STUDENT METACOGNITION ABILITY LEVEL

\begin{tabular}{|c|c|c|c|}
\hline No & Score Interval & The Number Of Students & Percentage \\
\hline 1 & $0 \leq$ SMS $\leq 45$ & 5 & 13 Percent \\
\hline 2 & $45 \leq$ SMS $\leq 5$ & 14 & 37 Percent \\
\hline 3 & $65 \leq$ SMS $₫ 00$ & 7 & 18 Percent \\
\hline 4 & $80 \leq$ SMS $\leq 90$ & 12 & 32 Percent \\
\hline 5 & $90 \leq$ SMS $\leq 00$ & 0 & 0 \\
\hline \multicolumn{3}{|r|}{ SMS : Student Metakognition Score }
\end{tabular}

Of the 38 students it turns out that the level of metacognition ability in low ability students has the highest proportion and is followed in high ability students. The level of metacognition ability of students with very low ability by 13 percent, low ability by 37 percent, medium ability by 18 percent and high ability by 32 percent. After carrying out learning using a jigsaw cooperative learning model on the material to build flat side space, continued tests on students to see students' mathematical connection abilities. Student answer sheets corrected based on scoring guidelines are graded. The level of mathematical connection ability of students is presented in Table 2 below.
TABLE 2 LEVELS OF MATHEMATICAL CONNECTION CAPABILITIES

\begin{tabular}{|c|c|c|c|}
\hline No & Score Interval & The Number Of Students & Percentage \\
\hline 1 & $0 \leq$ SKMS $\leq 45$ & 6 & 16 Percent \\
\hline 2 & $45 \leq$ SKMS $\leq 65$ & 15 & 39 Percent \\
\hline 3 & $65 \leq$ SKMS $\leq 80$ & 11 & 29 Percent \\
\hline 4 & $80 \leq$ SKMS $\leq 90$ & 6 & 16 Percent \\
\hline 5 & $90 \leq$ SKMS $\leq 00$ & 0 & 0 \\
\hline
\end{tabular}

SKMS : Student's Math Connection Score

Of the 38 students it turned out that the level of mathematical connection ability test students on low ability students had the highest proportion and followed at medium ability students where the level of mathematical connection ability of students with very low ability was 16 percent, low ability was 39 percent, ability while as much as 29 percent and high ability' as much as 16 percent.The process of answer metacognition and mathematical connections of students related to mathematical objects and with regard to the process of solving answers to problems of metacognition and mathematical connections do not conflict with agreements that already exist in mathematics both facts, concepts, principles and procedures.

Analysis of students' metacognition difficulties, students cannot write what is known to the problem, students also cannot apply the information obtained in the concepts they have thought, students cannot determine the initial steps that must be done in solving problems, students cannot solve problems correctly. In the analysis of students' mathematical connection difficulty, students cannot connect the information in the problem with the previous material correctly, students can relate the material to build flat side space with physics subject matter but it is not true, students cannot connect the material to build flat side space with physics subject matter but not correct and students are not able to connect real-life problems to the problem of getting up the flat side space.

\section{CONCLUSION}

Based on the results and discussion and findings during learning with the Jigsaw cooperative learning model, several conclusions are obtained which are answers to the research questions, the conclusions are:

1 The level of metacognition ability of 38 students with metacognition ability of students very low as much as 13 percent, ability kemampuan low as much as 37 percent, ability 'medium as much as 18 percent and high ability as much as 32 percent.

2 The level of mathematical connection ability of students of 38 people with 'very low' ability as much as 16 percent, low ability as much as 39 percent, moderate ability as much as 29 percent and high ability as much as 16 percent.

3 After the student answer process is described then concluded in the process of answer metacognition and mathematical connections students answer with mathematical objects and regarding the process of solving answers to problems of metacognition and mathematical 
connections related to linkages with those in mathematics with good questions, concepts, solutions that help the process.

4 Analysis of metacognition difficulties and mathematical connections of students is the analysis of metacognition difficulties of students, students can not understand what is in accordance with difficulties, students also can not use the information obtained in the concepts they think, students can not choose the steps that must be done in solving problem, students can not solve the problem correctly. In the analysis of students' mathematical connection difficulty, students cannot relate the information in the problem with the previous material, students can avoid the material build up flat side spaces with physics subjects not yet correct, students cannot avoid material material not yet correct and students are unable to overcome real life problems in the matter of building a flat side room

\section{REFERENCES}

[1] NCTM .(2000). Principles and Standards for School Mathematics. Narional Council of Theacher of Mathematics: US.

[2] Hasratuddin. 2015. Why Study Math? Medan: Prime Publishing.

[3] Chairani, Zahra. (2016). Student Metacognition in Mathematical Problem Solving. Yogyakarta: Depublish.

[4] Wilson, J Clarke, D. (2004). Towards The Modeling Of Mathematical Metacognition, Mathematics Education Research Journal.

[5] Rohendi, Dedi, Jojoj Dulpaja. (2013). Connected Mathematics Project (CMP) Model Based On Presentation Media To The Mathematical Connection Ability Of Junior High School Student. Journal Of Education And Pratice.

[6] Rusman. (2010). Learning Models, Bandung: Rajawali.

[7] Sugiyono. (2009). Educational Research Methodology. Bandung: ALFABETA.

[8] Trianto. (2009). Designing Innovative-Progressive Learning Models. Jakarta: Kencana Prenada Media Group 